\title{
Transmission Capacity Between Norway and Germany - a Real Options Analysis
}

\author{
Stein-Erik Fleten ${ }^{a}$, Ane Marte Heggedal ${ }^{a, *}$, Afzal Siddiqui $^{b}$ \\ ${ }^{a}$ Department of Industrial Economics and Technology Management, \\ Norwegian University of Science and Technology, NO-7491 Trondheim, \\ stein-erik.fleten@iot.ntnu.no, ane.m.heggedal@iot.ntnu.no \\ ${ }^{b}$ Department of Statistical Science, University College London, Gower Street, \\ London WC1E 6BT, afzal@stats.ucl.ac.uk \\ * Corresponding author
}

June 30, 2010

\begin{abstract}
Interconnection of two electricity markets provides revenues to the owner of the line. In this paper we study the alternatives open to an investor holding a unique right to construct transmission capacity between Norway and Germany. The alternatives are either constructing a $700 \mathrm{MW}$ cable with a subsequent expansion option, or to construct a $1400 \mathrm{MW}$ cable. We use a real options valuation (ROV) framework to decide which capacity should be chosen, and when the investment should be carried through. Our scientific contribution is to apply the ROV framework where sequential investment is allowed on transmission capacity investment. Further, we combine information from a bottom-up model, which estimates the reduction in average price differences due to the investment itself, and a top-down model for finding the values and optimal decisions.
\end{abstract}

Keywords: Real options, transmission capacity, electricity markets, expansion option

\section{Introduction}

Given that the price of a commodity is different in two regions, economic theory suggests that the commodity will be traded until an equilibrium price is reached. From a transmission capacity perspective, this suggests that additional transmission capacity between two regions will be added until the price of electricity is equal in the two regions, adjusted for long-term average transportation costs. This paper aims at analyzing the economic profitability and the optimal timing of investment in new transmission capacity interconnecting two electricity markets, taking uncertainty into account, and thereby providing an improved decision support for investors. Our scientific contribution lies within the use of real options valuation (ROV) where sequential investment is allowed, applied to transmission capacity investment. Further, we contribute by combining information from a bottom-up model, which estimates the reduction in average price differences due to the investment itself, and a top-down model for finding the ROV parameters.

The revenues to a transmission grid owner accrue mainly from the new price difference between the two regions being interconnected. In order to estimate the revenues from a high voltage direct current (HVDC) cable, we need to model the electricity price. There are two main ways for doing this, namely bottom-up and top-down modeling. A bottom-up model describes the constraints in a system very accurately. It 
may include production- and transmission constraints and electricity demand. The parameters required in the model can be either endogenous or exogenous. The effect of increased transmission capacity in the system can be found by running the model with and without the cable, ceteris paribus. A topdown model, on the other hand, describes the electricity price over the cable as the sum of one or more stochastic processes. While a bottom-up model requires a description of the system that is very accurate, the top-down model does not require the same detailed level of market information. Instead, it requires only the properties of the price processes at each of the nodes, or the properties of the price difference directly.

For bottom-up modeling of the Nordic electricity market, models such as the Balmorel (Elkraft System, 2009), the EMPS (SINTEF Energy Research AS, 2009), and Econ Bid (Econ Pöyry, 2009) can be used. Böhringer (1998) uses a bottom-up model for representing the energy sector in policy modeling, while Siddiqui and Gupta (2007) represent the price flow directly by using a top-down model when analyzing investment in new transmission capacity.

Two particular characteristics of electricity prices are seasonality and spikes. Lucia and Schwartz (2002) develop price models for the Nordic electricity market that include seasonal components to capture the effects of the variation in inflow and demand, in addition to a stochastic component. Fuss et al. (2008) model the German electricity market as a mean-reverting process. Deng (1999) introduces a meanreverting jump diffusion model to capture the spikes that are characteristic of energy markets. Spikes in the electricity price and the modeling of these are also studied by Weron et al. (2004), Lu et al. (2005) and Borovkova and Permana (2006).

Bunn and Zachmann (2010) discuss how the revenues from a cable may differ from the arbitrage possibility due to market power and the characteristics of the capacity trade. They argue that market participants may use market power to ensure higher prices in their own regions and that transmission capacity, when auctioned before the spot market closes, should be viewed as options on the spread of the electricity prices in the two interconnected countries/markets.

When the technologies used for electricity production in two regions are different, they may result in different price volatilities and levels. That is, distinct technologies create structural differences in the electricity price. In 2008, Germany had $126.7 \mathrm{GW}$ of installed electric power capacity (EIA, 2008), of which $23.9 \mathrm{GW}$ was wind power (Deutsches Windenergie-Institut, 2008). With $\mathrm{CO}_{2}$-emissions expected to be reduced by $18 \%$ by 2020 (European Commission, 2008), investment in renewable energy resources, such as wind, is required. Since most of the existing production facilities are thermal power plants, it is expensive and challenging to adjust the production. The demand for electricity fluctuates, and thereby creates a distinct price pattern over the day. Norway, on the other hand, has a power system where $98 \%$ of the electricity is produced by hydropower plants, and the total storage capacity corresponds to approximately $65 \%$ of the annual domestic consumption (Nordel, 2008). Storing water in the reservoirs enables power producers to use water during daytime when demand is high and reduce production in the night when demand is low. Figure 1 displays the median electricity price for every hour of the week in Germany (the Phelix on the European Energy Exchange, EEX) and the median spot price in southern Norway (NO1 on Nord Pool) for the years 2006 through 2009. Household demand for electricity is more elastic in Germany compared to in Norway due to the German market having more substitutes for electricity and the Norwegian use of electricity for heating purposes (Haas and Schipper, 1998). This, in addition to the differences in production technologies, creates the differences in the electricity prices illustrated in Figure 1.

Intraday price differences between Norway and Germany constitute one of the foundations for the revenues from transmission capacity. Hence, average prices will not capture the potential profitability of the cable, and the price difference must be modeled at an hourly level. Guthrie and Videbeck (2007) offer insight to such historical intraday price variation and how a spike in the electricity price affects the electricity price over the following period of time. Elverhøi et al. (2009) model intraday price variation as a deterministic price adjustment, where the size of the adjustment depends on the weekday and the season. 


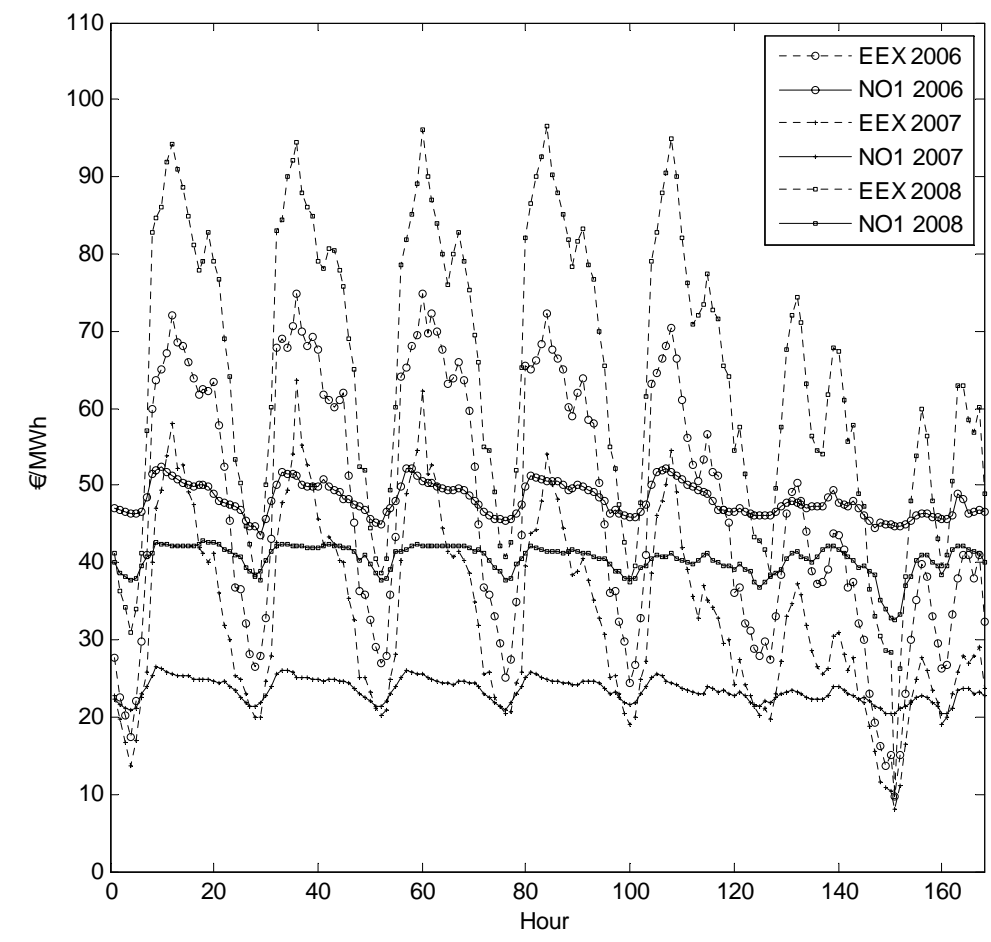

Figure 1: Historical median price development over the week, southern Norway (NO1) and Germany (EEX).

When trading in two currencies, the exchange rate affects the profit flow of the company. Therefore, the exchange rate uncertainty must be included when analyzing investment alternatives where the revenues depend on the exchange rate. Engel and West (2004) summarize the status quo for exchange rate models and expand the literature by studying the effect on exchange rate when the discount factor is close to unity. Mussa (1979) finds that the logarithm of the US exchange rates approximately follow a random walk. Chortareas et al. (2002), on the other hand, find that real exchange rates in the G7 countries, using the authors' testing framework, have evidence of nonlinear mean reversion in most cases whereas the standard Dickey-Fuller test based on the linear model cannot support this evidence.

The value of an investment opportunity where timing and capacity are important factors, can be captured by using real options valuation (ROV). Dixit and Pindyck (1994) develop and outline the ROV framework where aspects concerning uncertainty in the investment analysis are taken into account. Fortin et al. (2008) conduct real options analysis using dynamic programming where they combine ROV and Conditional Value-at-Risk (CVaR) portfolio optimization to analyze the optimal composition of the electricity mix. Investment problems where optimal timing and optimal capacity has to be chosen at the same time is studied by Dangl and Wirl (2004), while Botterud (2003) includes construction delays when conducting ROV in new power generation. Joskow and Tirole (2005) elaborate on the incentive of getting a toehold by sinking a small investment, while Newton et al. (2004) give a review of the research on real R\&D options. Décamps et al. (2006) present irreversible investment in different projects where the authors expand the literature to allow for switching one project in favor of another project, and thereby revealing how the investment region is dichotomous.

In order to calculate the value of ordinary financial options, one needs the market value of the underlying asset and the corresponding future dynamics. These dynamics are variables that affect the option value, and hence are included in the real options valuation. Real projects are non-traded assets and cannot easily be replicated. Various approaches exist to solve or circumvent this problem. Trigeorgis (1996) advocates, as is done in pricing of financial options, to find a twin security for the pricing of real options. In this approach, the real option is assumed to have the same dynamics as the twin security, and, hence, 
the real option can be priced using the attributes, such as the volatility, of the twin security (Trigeorgis, 1996). Copeland and Antikarov (2003) introduce the marketed asset disclaimer (MAD) assumption. The essence of this approach is that instead of searching in financial markets for replicating portfolios, one can use the present value of the project itself as if it was a marketed security. Godinho (2006) criticizes the volatility estimations of Copeland and Antikarov (2003), demonstrating how the latter approach overestimates the volatility of the investment projects. He also suggests an alternative way of estimating the volatility, where the parameters are found by extending the present value simulations (Godinho, 2006).

The Act relating to the generation, conversion, transmission, trading, distribution and use of energy in the Norwegian laws states that an investor must apply for a license to construct a facility (power plant, transmission capacity, etc.), and that the lifetime of the license is limited (Norwegian Government, 2010). An investor who wishes to build transmission capacity between Norway and Germany must, therefore, apply to the Norwegian Water Resources and Energy Directorate for a license to build the submarine cable. If the company does not build the transmission capacity within the time limit, then the license is withdrawn.

By having a limited time grant, the company loses parts of the option value embedded in the license to construct transmission capacity. By estimating the difference between the option value and the net present value (NPV) of the investment project, we find the value lost to the company and, hence, to society, when not including the option value in the calculations.

Electricity can be transported between regions using the transmission grid. Depending on the distance, landscape, and the use of the grid, different technologies are optimal. The choice of technology for transmission capacity depends on many factors. Song and Johns (2006) describe the alternating current (AC) technology and its properties, while Bahrman and Johnson (2007) focus on the HVDC technology and its use. The investment alternatives studied in this paper incorporate the use of HVDC technology.

The goal of our analysis is to conduct a real options analysis of the investment opportunity of constructing transmission capacity between Norway and Germany. We take the perspective of an investor holding the option to invest and we find the optimal investment time and discuss how a time limited license affects social welfare. In order to conduct our ROV, we first construct a framework for evaluating the NPV of each investment alternative in Section 2. Through this analysis, we find the parameters required in the ROV. Next, we build a model to estimate the real options value in Section 3. Section 4 provides numerical results and analysis, while Section 5 concludes and outlines suggestions for further work in this area.

\section{Net Present Value Model}

In order to model the revenues from transmission capacity between two regions, we need to represent the process of the electricity price difference between the regions. We have chosen to model the electricity price difference as a top-down model, where we take the results from a bottom-up model into account. The top-down approach is a simplification that allows us to use a single stochastic process rather than the sum of two stochastic processes to model the price difference between Norway and Germany. We assume that the investor receives the congestion rent along the line, which is equal to the ex post price difference between the two nodes. The congestion rent is represented through the modeling of the electricity price difference between the Phelix price on the EEX and the NO1 price (southern region in Norway) on Nord Pool. Since the trade in electricity is quoted in Euro and the income statement and accounts of Norwegian power companies are in Norwegian kroner, the Norwegian partners are exposed to exchange rate uncertainty. In addition, the revenues from the cable depend on the technical constraints and the costs associated with the cable. The outputs from the NPV analysis are the volatility and drift parameters for the ROV, in addition to a scaling parameter, which we use when representing the annual revenues from the $1400 \mathrm{MW}$ cable as a function of the revenues from the $700 \mathrm{MW}$ cable. Next, we introduce our electricity price and exchange rate models, in addition to the technical constraints and the parameter 
estimation for the ROV.

\subsection{Electricity Price Difference Model}

The intraday characteristics of the electricity price difference between Norway and Germany is captured by modeling the electricity price with a time resolution of one hour. The electricity price difference model consists of three parts, where the first part represents the deterministic variation in the difference and the second part represents the stochastic annual price difference level. The third part captures the stochastic variation in the electricity price difference. The final price difference model is the sum of all three parts, as outlined in Eq. (1):

$$
P_{t}=d_{t}+a_{t}+s_{t}, \quad t \in \mathcal{T}
$$

where $d_{h}$ is the deterministic part of the model containing the hourly, weekly, and monthly characteristics, $a_{t}$ is the (stochastic) annual price difference level, and $s_{t}$ is the residual stochastic part of the model. $\mathcal{T}$ is the set over which we simulate the future electricity price difference between Norway and Germany.

In the deterministic part of the model, we include seasonality for the hourly, weekly, and monthly price difference. When conducting the regression analysis in order to find the parameters for the seasonality, we include the year as a dummy variable for use in the second part of the price model, namely the annual price difference level. The regression is conducted using ordinary least squares (OLS) and the model is given by the following equation:

$$
\begin{aligned}
e_{h}= & \phi+\gamma_{i} \cdot \text { hour }_{i}+\pi_{j} \cdot \text { weekday }_{j}+\kappa_{m} \cdot \text { month }_{m}+\eta_{n} \cdot \text { year }_{l}+\epsilon_{h}, \\
& h \in \mathcal{H}, i \in \mathcal{I}, j \in \mathcal{J}, m \in \mathcal{M}, n \in \mathcal{N}
\end{aligned}
$$

The historical hourly electricity price difference is represented by $e_{h}$ and $\mathcal{H}$ is the set of all hourly price differences in the sample. The set $\mathcal{I}$ contains all hours of the day from hour 2 to hour 24 , while $\mathcal{J}$ is the set of all days of the week from Tuesday to Sunday. $\mathcal{M}$ is the set of the months from February to December and $\mathcal{N}$ is the set of years included in the sample. The parameters for the dummy variables are given by $\gamma_{i}, \pi_{j}, \kappa_{m}$, and $\eta_{n}$, and they represent the hourly, weekly, monthly and yearly seasonality, respectively. In order to avoid the dummy variable trap, ${ }^{1}$ the reference time is set to the first hour of the day, Monday, January, and 2003. ${ }^{2}$ The constant is represented by $\phi$ and the disturbance term is given by $\epsilon_{h}$.

When simulating the future electricity price differences, the model will consist of three parts. The first part of the model, denoted $d_{t}$, is given by the following equation:

$$
\begin{aligned}
\hat{d}_{t}= & \hat{\gamma}_{i} \cdot \text { hour }_{i}+\hat{\pi}_{j} \cdot \text { weekday }_{j}+\hat{\kappa}_{m} \cdot \text { month }_{m}, \\
& t \in \mathcal{T}, i \in \mathcal{I}, j \in \mathcal{J}, m \in \mathcal{M}
\end{aligned}
$$

Where $\hat{\gamma}_{i}, \hat{\pi}_{j}$ and $\hat{\kappa}_{m}$ are the estimated values from the regression given in Eq. (2). The set $\mathcal{T}$ consists of all the hours in the period we simulate.

The annual price difference level changes every year due to the Norwegian dependence on inflow to the water reservoirs and the differences in production technologies in the two countries. This effect is accounted for in the second part of our electricity price difference model. We use the historical price levels from the regression analysis given in Eq. (2) to find the average annual price difference level $(\bar{\theta})$, as represented in the following equation:

$$
\bar{\theta}=\hat{\phi}+\frac{\Sigma_{n=2003}^{2009} \hat{\eta}_{n}}{7}
$$

\footnotetext{
${ }^{1}$ If all the dummy variables are included, we get perfect multicollinearity. This is referred to as the dummy variable trap.

${ }^{2}$ This is the first year of our observations.
} 
The estimates for $\hat{\eta}$ are found with the help of Eq. (2). Note that $\hat{\eta}_{2003}$ has the value zero. The volatility of the annual price difference level, $\varrho$, is given as the standard deviation of the historical annual price level.

When simulating the future historical annual price difference level, we use the approach outlined in Eq. (5):

$$
\theta_{y}=\bar{\theta}+\varrho \cdot \xi_{y}, \quad \xi_{y} \sim N(0,1), \quad y \in \mathcal{Y}
$$

where $\theta_{y}$ is the annual price level for year $y, \bar{\theta}$ is the mean annual price difference level, and $\varrho$ is the standard deviation of the annual price difference level. $\mathcal{Y}$ is the set of all the years in our simulations. We denote the annual price level for each hour by $a_{h}$, where the annual price level is the same for every hour within the year. That is; $a_{t}$ from $t=1$ to $t=8760$ is equal to $\theta_{1}$ and $a_{t}$ from $t=8761$ to $t=17520$ is equal to $\theta_{2}$ etc. By modeling the annual price level in this way, we may include information from the forward market or information about how the decision maker believes the price difference between Norway and Germany will change over lifetime of the investment opportunity.

After extracting the seasonality and the annual price difference level from the historical data, the residuals are not white noise. In order to capture the true characteristics of the price difference process, we store the residuals from the regression analysis and use these in simulating the future electricity price difference. This is the third and final part of our price model. When simulating, we use bootstrapping techniques and draw 24 residuals at a time, one for each hour of the day. The residuals are denoted by $s_{t}$ and we draw 24 consecutive observations, always starting on the first hour of the day, to correct for the autocorrelation within the residuals.

The estimated parameters for the electricity price difference model are found using ordinary least squares (OLS). The results from the regression are summarized in Table 4 in the Appendix. ${ }^{3}$

As can be seen from Table 4 in the Appendix, the majority of the parameters are significant. The regression diagnostics are summarized in Table 1.

Table 1: Regression diagnostics of Eq. (2).

\begin{tabular}{ll}
\hline Coefficient & Result \\
\hline$R^{2}$ & 0.295 \\
$F(46,61321)$ & $558.6[0.000]^{* *}$ \\
$D W$ & 0.733 \\
number of observations & 61368 \\
number of parameters & 47 \\
mean(Phelix - NO1) & 7.699 \\
$\operatorname{var}($ Phelix - NO1) & 964.548 \\
\hline
\end{tabular}

The coefficient of determination $\left(R^{2}\right)$ of the regression is 0.3 . We consider this acceptable since we include the residuals, and thereby include the information retained in the residuals, in our simulations. The Durbin Watson (DW) parameter tells that there is autocorrelation in the residuals. As mentioned, we take account for this in the use of the residuals from the regression in the simulations. The F-value states that together, the estimates for all the parameters are significant.

The parameters for the electricity price difference level and its volatility are summarized in Table 5 in the Appendix.

\footnotetext{
${ }^{3}$ The data span the period from 01.01.2003 to 31.12.2009.
} 


\subsection{Exchange Rate Model}

The trade of electricity in both Norway and Germany is quoted in $€ / M W h$. Since the income statement and accounts of Norwegian companies are noted in Norwegian kroner, we need to take the NOK/€ exchange rate into account when considering the profitability of a submarine cable between Norway and Germany from the perspective of a Norwegian owner. Historical exchange rates from the years 2007, 2008 and 2009 are presented in Figure 2.

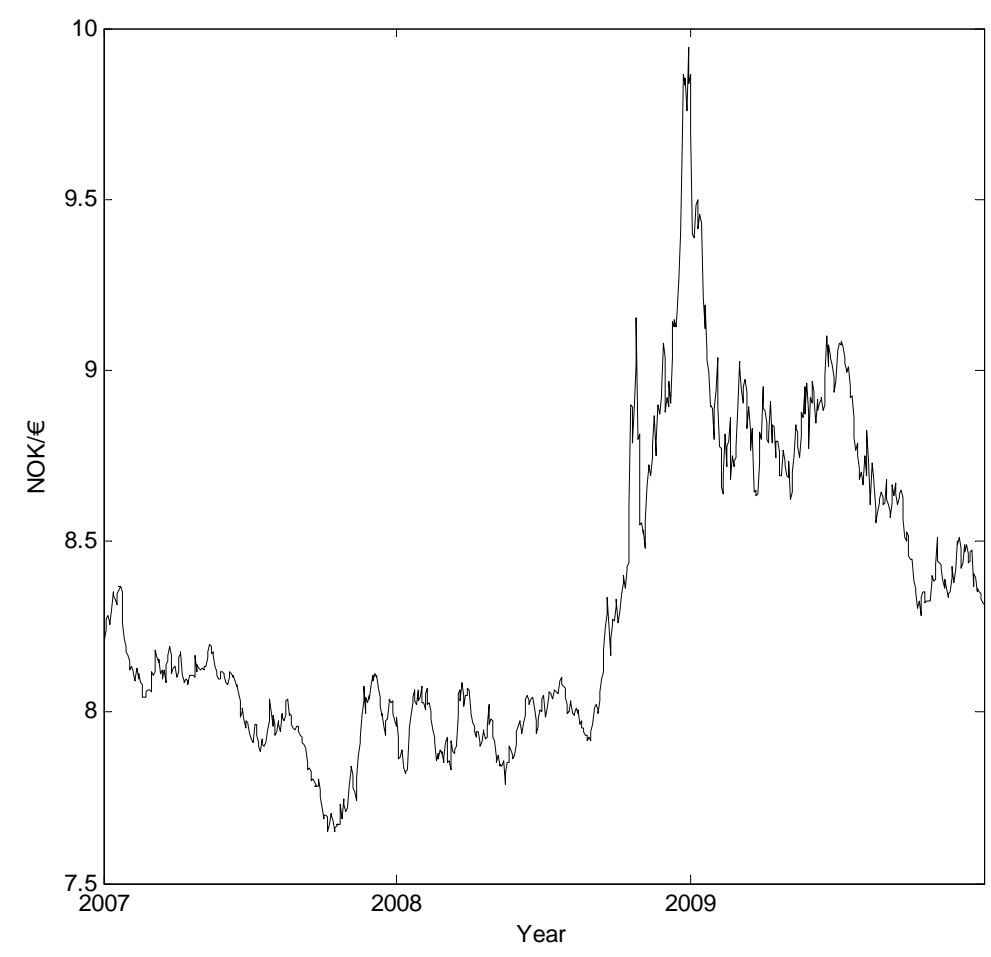

Figure 2: Historical NOK/€ exchange rates for the years 2007, 2008 and 2009.

Like Mussa (1979), we choose to include the exchange rate uncertainty by modeling the logarithm of the exchange rate as a random walk, as given in Eq. (6):

$$
\log \left(E_{t}\right)=\log \left(E_{t-1}\right)+\varpi \cdot \sqrt{\frac{1}{365}} \cdot \lambda_{t}, \quad \lambda \sim N(0,1), \quad t \in \mathcal{T}
$$

The exchange rate on day $t$ is represented by $E_{t}$, while the volatility of the exchange rate is represented by $\varpi$. The electricity price difference varies for every hour of the day. The exchange rate on the other hand is the same for every hour within the day.

The volatility of the random walk in the exchange rate is found by taking the standard deviation of the logarithm of the NOK/€ exchange rate. ${ }^{4}$ The parameters for the exchange rate model are summarized in Table 6 in the Appendix.

\subsection{Technical Considerations}

The alternatives for investment considered in this analysis are either a $700 \mathrm{MW}$ submarine cable with the compound option on an additional $700 \mathrm{MW}$, or a $1400 \mathrm{MW}$ submarine cable. In addition to the size of the cable, the loss, capacity, lifetime, and the maintenance costs affect the profitability of a cable.

\footnotetext{
${ }^{4}$ The data spans the period from 01.01.2003 to 31.12.2009.
} 
In Statnett's studies of the NorNed cable (a 600 MW submarine HVDC cable interconnecting Norway and the Netherlands), transmission losses are estimated to be $4 \%$ at $600 \mathrm{MW}$ and $5 \%$ at $700 \mathrm{MW}$ (Statnett, 2004). In the same report, Statnett conclude that the NorNed cable will have an expected lifetime of (minimum) 40 years. The annual cost of maintaining a $600 \mathrm{MW}$ submarine cable is $€ 4$ million, and its availability is $97.4 \%$ (Statnett, 2004).

The technical parameters for the NorGer cable are summarized in Table 7 in the Appendix. We choose to use the same annual costs, availability, and loss as Statnett employed in the studies of the NorNed cable. Losses from ramping are neglected since they take place when the price difference between the connected regions is low, and, hence, do not affect the revenues of the cable to any great extent. For simplification, we assume that capacity, lifetime, maintenance costs, and losses are constant. We also assume that the maintenance costs for a $1400 \mathrm{MW}$ cable is twice those of a $700 \mathrm{MW}$ cable.

The number of suppliers of submarine cables is limited, which also is the case for lay vessels and trenching spreads. We chose to not take this into consideration when analyzing the investment opportunity. Also, we include neither construction lags nor the possibility of selling system services in our analysis. Construction lags would tend to favor the investment alternative with the shortest construction time, which is the smaller investment alternative. The opportunity of selling systems services, on the other hand, would tend to favor the investment alternative with the greater capacity due to the increased revenues. Neither of these characteristics will be discussed in the following.

\subsection{Bottom-up Model Contribution}

When interconnecting two regions, there is reason to believe that the increased transmission capacity will affect the prices in the two regions. The changes in prices will depend on the size of the new capacity and the technical limitations of the transmission grids in the two regions. SINTEF Energy Research has conducted a bottom-up analysis using the EMPS model. ${ }^{5}$ The data in the model are provided by Statnett. Using their results, we extract the effect of interconnecting Norway and Germany. We find that interconnecting the two markets will decrease the electricity price difference by approximately $8 \%$ and $17 \%$ in the case of $700 \mathrm{MW}$ and $1400 \mathrm{MW}$ cables, respectively. The EMPS model estimates the daily price difference reduction due to the cable. We assume that this reduction also is applicable at an hourly price resolution.

\subsection{Annual Revenues}

The present value of the revenues over the lifetime of the cables are assumed to follow a geometric Brownian motion (GBM). This is in accordance with Copeland and Antikarov (2003), who base their theory on Samuelson's proof that the rate of return on any security will be a random walk regardless of the pattern of cash flows that it is expected to generate in the future as long as the investors have complete information about these cash flows (Samuelson, 1965). Since the only underlying stochastic process of the project value is the revenue from the cable, the stochastic process of the returns on the annual revenues and the returns on the project value will have the same volatility. In order to find the drift and volatility of the project value, we can, therefore, focus on the qualities of the annual revenues from the cable. Note that the annual revenues are a function of the difference in the electricity price between the interconnected regions, the exchange rate and the technical parameters of the cable. The annual revenues (8760 hours) from a 700 MW cable and a 1400 MW cable can be summarized as in Eq. (7) and Eq. (8), respectively:

$$
\begin{gathered}
\hat{R}_{700}=\Sigma_{i=1}^{8760}\left[\left(P_{i} \cdot c_{700} \cdot b \cdot(1-k) \cdot\left(1-u_{700}\right)-q_{700}\right) \cdot E_{i}\right] \\
\hat{R}_{1400}=\Sigma_{i=1}^{8760}\left[\left(P_{i} \cdot c_{1400} \cdot b \cdot(1-k) \cdot\left(1-u_{1400}\right)-q_{1400}\right) \cdot E_{i}\right]
\end{gathered}
$$

\footnotetext{
${ }^{5}$ See http://www.sintef.no/Home/Petroleum-and-Energy/SINTEF-Energy-Research/Software/EOPS-and-EMPS/ for documentation of this model.
} 
where $P_{i}$ is the electricity price difference in hour $i, c_{700}$ and $c_{1400}$ are the capacities of the cable $700 \mathrm{MW}$ and $1400 \mathrm{MW}$ cable, respectively, $b$ is the availability of the cable and $k$ is the electricity loss when using the cable. The price difference reduction due to the cable is given by $u_{700}$ for the $700 \mathrm{MW}$ cable and $u_{1400}$ for the $1400 \mathrm{MW}$ cable. Annual costs are given by $q_{700}$ and $q_{1400}$, for the $700 \mathrm{MW}$ and the $1400 \mathrm{MW}$ cable alternative respectively, and the exchange rate in hour $i$ is given by $E_{i}$.

\subsection{Parameters to the ROV}

The parameters required for the real options valuation are the drift $(\mu)$ and volatility $(\sigma)$ of the projects. In addition, a scaling factor, $\delta$, will be used to represent the revenues from the $1400 \mathrm{MW}$ cable as a function of the revenues from the $700 \mathrm{MW}$ cable. The discount factor is given by $\rho$.

Since the volatility and drift of the return of the project value are the same as the volatility and drift of the returns on the annual revenues, we find the volatility and drift of the return on the project as the standard deviation and drift of the return on the annual revenues. The volatility is found by using the approach suggested by Godinho (2006), using the two-level simulation procedure. Where Godinho (2006) finds the average cash flows after the first year, we use the average annual revenues.

As mentioned in Section 2.4, the price difference between Norway and Germany will change due to the interconnection of the two regions. In the real options valuation, we model the revenues from the $1400 \mathrm{MW}$ cable as a linear function of the revenues from the $700 \mathrm{MW}$ cable. In order to find how much greater the revenues from the $1400 \mathrm{MW}$ cable are ${ }^{6}{ }_{\text {we }}$ conduct an NPV analysis of both projects, find the average present values of both projects, ${ }^{7}$ and find the scaling factor, $\delta$, as given in Eq. (9):

$$
\delta=\frac{\hat{R}_{1400}}{\hat{R}_{700}}
$$

where $R_{700}$ are the annual revenues from a $700 \mathrm{MW}$ cable and $R_{1400}$ are the annual revenues from a $1400 \mathrm{MW}$ cable. The parameters for the real options valuation are found using the Monte Carlo procedure described in Godinho (2006) with 1500 iterations in the first level simulation and 500 iterations in the second level simulation, and are summarized in Table 8 in the Appendix.

\section{Real Option Valuation}

The investment alternatives under consideration are a $700 \mathrm{MW}$ cable with a subsequent expansion option and a $1400 \mathrm{MW}$ cable. We model an investment opportunity in a $700 \mathrm{MW}$ cable with an embedded upgrade option in the same fashion as the Décamps et al. (2006) model a switching option. Where Décamps et al. (2006) switches between two individual projects, we switch between the $700 \mathrm{MW}$ project and the $1400 \mathrm{MW}$ project by allowing the $700 \mathrm{MW}$ alternative to be upgraded to $1400 \mathrm{MW}$. We assume that the investment cost of expanding the $700 \mathrm{MW}$ cable is the same as the cost of investing in the $700 \mathrm{MW}$ cable in the first place. There are technical constraints and costs associated with the different projects. The parameters are summarized in Table 2.

\footnotetext{
${ }^{6}$ The $1400 \mathrm{MW}$ cable will reduce the price difference more, compared to the $700 \mathrm{MW}$ cable. This is due to the greater supply of capacity provided by the $1400 \mathrm{MW}$ cable compared to the capacity provided by the $700 \mathrm{MW}$ cable. This implies that the $1400 \mathrm{MW}$ will yield revenues less than twice the revenues of the $700 \mathrm{MW}$ cable.

${ }^{7}$ The present value of investment alternatives are denoted by $r_{700}$ and $r_{1400}$ for the $700 \mathrm{MW}$ and $1400 \mathrm{MW}$ alternative, respectively.
} 
Table 2: Notation for the real options valuation (ROV).

\begin{tabular}{ll}
\hline Abbreviation & Explanation \\
\hline$y$ & Time, in years \\
$V_{700}$ & NPV of a $700 \mathrm{MW}$ cable \\
$V_{700}$ & OpV of a $1400 \mathrm{MW}$ cable \\
$\mathcal{V}$ & Annual present value of revenues from a $700 \mathrm{MW}$ cable \\
$R_{700}$ & Annual present value of revenues from a $1400 \mathrm{MW}$ cable \\
$R_{1400}$ & Current value of annual present value of revenues from a $700 \mathrm{MW}$ cable \\
$r_{700}$ & Current value of annual present value of revenues from a $1400 \mathrm{MW}$ cable \\
$r_{1400}$ & Investment cost for a $700 \mathrm{MW}$ cable \\
$K_{700}$ & Investment cost for a $1400 \mathrm{MW}$ cable \\
$K_{1400}$ & Output from a $700 \mathrm{MW}$ cable \\
$X_{700}$ & Output from a $1400 \mathrm{MW}$ cable as a fraction of a $700 \mathrm{MW}$ cable \\
$X_{1400}$ & Discount rate \\
$\rho$ & Drift of a $700 \mathrm{MW}$ and a $1400 \mathrm{MW}$ cable \\
$\mu$ & Volatility of a $700 \mathrm{MW}$ and a $1400 \mathrm{MW}$ cable \\
$\sigma$ & Factor of which to multiply annual revenues from a $700 \mathrm{MW}$ project \\
$\delta$ & to get annual revenues from a 1400 MW project \\
\hline
\end{tabular}

We assume that the present value of the $1400 \mathrm{MW}$ cable can be described as a function of the present value of the $700 \mathrm{MW}$ cable, where the scaling factor is given by $\delta$ in Eq. (9). We analyze the investment opportunity by using the annual present value of the revenues as state variable. Hence, $X_{700}$ is one and $X_{1400}$ is the scaling parameter $\delta$ multiplied by $X_{700}$. Both project values are assumed to have the same drift and volatility.

We assume that the project value of both the $700 \mathrm{MW}$ and the $1400 \mathrm{MW}$ alternatives follow a GBM, as given by Eq. (10) and Eq. (11):

$$
\begin{gathered}
\Delta R_{700}(y)=\mu \cdot R_{700}(y) \Delta t+\sigma \cdot R_{700}(y) \cdot \Delta W(y), \quad y \in \mathcal{Y} \\
\Delta R_{1400}(y)=\delta \cdot \Delta R_{700}(y), \quad y \in \mathcal{Y}
\end{gathered}
$$

$\mathcal{Y}$ is the set of all the years in our simulations. The NPV of a $700 \mathrm{MW}$ cable includes the discounted value of the annual revenues of the project minus the investment cost plus a compound option to expand the cable to twice its size. For the current value of the revenues from a $700 \mathrm{MW}$ cable, $r_{700}$, the NPV of the project can be found, as given in Décamps et al. (2006), by solving Eq. (12) and Eq. (13):

$$
\begin{gathered}
V_{700}\left(r_{700}\right)=\Sigma_{i=1}^{40} \frac{r_{700} \cdot X_{700}}{(1+(\rho-\mu))^{i}}-K_{700}+\left(\frac{r_{700}}{r_{12}}\right)^{\beta} \cdot \frac{K_{700}}{\beta-1} \quad \text { if } r_{700} \leq r_{12} \\
V_{700}\left(r_{700}\right)=\Sigma_{i=1}^{40} \frac{r_{700} \cdot X_{1400}}{(1+(\rho-\mu))^{i}}-2 \cdot K_{700} \quad \text { if } r_{700}>r_{12}
\end{gathered}
$$

where

$$
r_{12}=\frac{\beta}{\beta-1} \cdot \frac{K_{700}}{\left(\sum_{i=1}^{40} \frac{1}{(1+(\rho-\mu))^{i}}\right) \cdot\left(X_{1400}-X_{700}\right)}
$$

and

$$
\beta=\frac{1}{2}-\frac{\mu}{\sigma^{2}}+\sqrt{\left(\frac{1}{2}-\frac{\mu}{\sigma^{2}}\right)^{2}+\frac{2 \cdot \rho}{\sigma^{2}}}
$$

The NPV of the cable is a function of the current value of the annual present value of revenues $\left(r_{700}\right)$, and the compound option embedded in the investment alternative. $r_{12}$ represents the annual revenues level at which the $700 \mathrm{MW}$ cable should be upgraded to a $1400 \mathrm{MW}$ cable, given that the investment 
in a $700 \mathrm{MW}$ cable has been undertaken. The NPV of $1400 \mathrm{MW}$ is the discounted value of the annual revenues of the project minus the investment cost of the project, and can be found by solving Eq. (16):

$$
V_{1400}\left(r_{1400}\right)=\Sigma_{i=1}^{40} \frac{r_{1400} \cdot X_{1400}}{(1+(\rho-\mu))^{i}}-K_{1400}
$$

Our approach differs from Décamps et al. (2006) in the following two ways: (1) The lifetime of the projects is not unlimited and (2) the cost of upgrading the $700 \mathrm{MW}$ alternative to $1400 \mathrm{MW}$ does not give the additional investment cost of the $1400 \mathrm{MW}$ alternative (as is assumed in Décamps et al. (2006)), but is the same as the initial cost of constructing a $700 \mathrm{MW}$ cable.

The option to invest in either a $700 \mathrm{MW}$ or a $1400 \mathrm{MW}$ cable may give a dichotomous investment region. As in Décamps et al. (2006), we have six price regions when considering an upgrade option, and these are given in Table 3 .

Table 3: Investment and waiting regions for the investment projects.

\begin{tabular}{ll}
\hline Annual revenues interval & Explanation \\
\hline$\left[0, r_{700,1}\right\rangle$ & Waiting region \\
{$\left[r_{700,1}, r_{700,3}\right\rangle$} & Invest in a $700 \mathrm{MW}$ cable and wait for opportunity to upgrade \\
{$\left[r_{700,3}, r_{700,4}\right\rangle$} & Waiting region \\
{$\left[r_{700,4}, \infty\right\rangle$} & Invest in a $1400 \mathrm{MW}$ cable \\
{$\left[r_{700,1}, r_{12}\right\rangle$} & Given investment in a $700 \mathrm{MW}$ cable is undertaken, \\
& this is a waiting region \\
{$\left[r_{12}, \infty\right\rangle$} & Given investment in a $700 \mathrm{MW}$ cable is undertaken, \\
& upgrade to a $1400 \mathrm{MW}$ cable \\
\hline
\end{tabular}

Over the interval $\left[0, r_{700,1}\right\rangle$, the value of the option to invest, $\mathcal{V}$, is given by Eq. (17):

$$
\mathcal{V}\left(r_{700}\right)=C \cdot r_{700}^{\beta}
$$

where $\beta$ is given by Eq. (15) and $C$ is given by Eq. (18), as suggested by Dixit and Pindyck (1994):

$$
C=\frac{1}{r_{700,1}^{\beta}} \cdot\left[\frac{K_{700}}{\beta-1}+\left(\frac{r_{700,1}}{r_{12}}\right)^{\beta} \cdot \frac{K_{700}}{\beta-1}\right]
$$

where $r_{12}$ is as given in Eq. (14). The investment threshold $r_{700,1}$ can be found by inserting Eq. (15) and Eq. (18) into Eq. (17), setting the option value (Eq. (17)) equal to the NPV of the 700 MW project (Eq. (12)) and solve for the variable $r_{700,1}$. This yields the following expression for finding $r_{700,1}$ :

$$
r_{700,1}=\frac{\beta}{\beta-1} \cdot \frac{K_{700}}{X_{700} \cdot \Sigma_{i=1}^{40} \frac{1}{(1+(\rho-\mu))^{i}}}
$$

Over the interval $\left[r_{700,1}, r_{700,3}\right\rangle$, the value of the $700 \mathrm{MW}$ cable equals the NPV of the project plus the value of the option to expand to $1400 \mathrm{MW}$. On the interval $\left[r_{700,3}, r_{700,4}\right\rangle$ there may be another waitingregion. That is, the investor waits to see whether investing in the $700 \mathrm{MW}$ cable or the $1400 \mathrm{MW}$ cable is the optimal action. In this area, the option takes the form as given in Eq. (20):

$$
\mathcal{V}\left(r_{700}\right)=A \cdot r_{700}^{\alpha}+B \cdot r_{700}^{\beta}
$$

where $\beta$ is given by Eq. (15) and $\alpha$ is given by Eq. (21):

$$
\alpha=\frac{1}{2}-\frac{\mu}{\sigma^{2}}-\sqrt{\left(\frac{1}{2}-\frac{\mu}{\sigma^{2}}\right)^{2}+\frac{2 \cdot \rho}{\sigma^{2}}}
$$

The optimal action for the interval $\left[r_{700,4}, \infty\right\rangle$ depends on the actions, which have already been undertaken at the time. If no action has been undertaken, then the optimal action is to invest in the $1400 \mathrm{MW}$ cable. 
If investment in the $700 \mathrm{MW}$ cable has been undertaken, the option value on the interval $\left[r_{700,1}, r_{12}\right\rangle$ is the value of the option to expand the project to $1400 \mathrm{MW}$. The optimal threshold to switch from $700 \mathrm{MW}$ to $1400 \mathrm{MW}$, given that the investment in the $700 \mathrm{MW}$ has been undertaken, is $r_{12}$.

In Eq. (20), the constants $A$ and $B$ are unknown. In order to find these constants, along with the values of $r_{700,3}$ and $r_{700,4}$, we use the properties of value matching and smooth-pasting. This means that the NPV of the projects and the option values in $r_{700,3}$ and $r_{700,4}$ must be the same. That is, let Eq. (12) be equal to Eq. (20), and also let the derivative of Eq. (12) be equal to the derivative of Eq. (20), in the point $r_{700,3}$. Further, let Eq. (16) be equal to Eq. (20), and also let the derivative of Eq. (16) be equal to the derivative of Eq. (20), in the point $r_{700,4}$. By this procedure, we get Eq. (22) to Eq. (25):

$$
\begin{aligned}
A \cdot r_{700,3}^{\alpha}+B \cdot r_{700,3}^{\beta} & =\sum_{i=1}^{40} \frac{r_{700,3} \cdot x_{1}}{(1+(\rho-\mu))^{i}}-K_{700}+\left(\frac{r_{700,3}}{r_{12}}\right)^{\beta} \cdot \frac{K_{700}}{\beta-1} \\
A \cdot r_{700,4}^{\alpha}+B \cdot r_{700,4}^{\beta} & =\sum_{i=1}^{40} \frac{r_{700,4} \cdot x_{1400}}{(1+(\rho-\mu))^{i}}-K_{1400} \\
\alpha \cdot A \cdot r_{700,3}^{\alpha-1}+\beta \cdot B \cdot r_{700,3}^{\beta-1} & =\sum_{i=1}^{40} \frac{X_{700}}{(1+(\rho-\mu))^{i}}+\beta \cdot r_{700,3}^{\beta-1} \cdot \frac{1}{r_{12}^{\beta}} \cdot \frac{K_{700}}{\beta-1} \\
\alpha \cdot A \cdot r_{700,4}^{\alpha-1}+\beta \cdot B \cdot r_{700,4}^{\beta-1} & =\sum_{i=1}^{40} \frac{X_{1400}}{(1+(\rho-\mu))^{i}}
\end{aligned}
$$

We get four equations and four unknowns, which we can solve numerically to find the values for $A, B$, $r_{700,3}$, and $r_{700,4}$. Through this method, we can find the values for the optimal time to invest in $700 \mathrm{MW}$ and the optimal time to invest in $1400 \mathrm{MW}$.

\section{$4 \quad$ Numerical Examples}

There are situations in which, no matter what the current value of the state variable is, it will never be optimal to invest sequentially, that is, first investing in a $700 \mathrm{MW}$ cable which is later upgraded to 1400 MW. In the framework of Décamps et al. (2006), the following condition must hold in order for sequential investment to be optimal:

$$
\frac{X_{700}^{\beta}}{K_{700}^{\beta-1}}>\left[1-\left(1-\frac{X_{700}}{X_{1400}}\right)^{\beta}\right] \cdot \frac{X_{1400}^{\beta}}{K_{1400}^{\beta-1}}
$$

This equation states that the relationship between costs and output must be of a certain order for the investment to happen sequentially. The inequality does not hold with our given set of parameters and, hence, investing sequentially is a dominated investment strategy.

Nevertheless, investing first in a $700 \mathrm{MW}$ cable, giving the option to expand to $1400 \mathrm{MW}$ at a later stage, can be interesting for reasons not included in this analysis. The construction of a $700 \mathrm{MW}$ cable allows the investor to expand its organization in a slower pace, and the investor will also gain experience with the HVDC technology. An additional consideration is the electricity markets in the two countries, and the so-called price areas. The Norwegian market is divided into five price areas whereas the German market has one price area. If this structure changes, the foundation for the revenues from a cable may change. Furthermore, unforeseeable events regarding technical and economic circumstances may occur. If these events extensively reduce the revenue generation from the investment, sinking a lower investment cost may be beneficial. These are effects not accounted for in our analysis, which suggests that sequential construction may be preferred. For these reasons, we glance into the optimal path of actions if the investor chooses to first invest in a $700 \mathrm{MW}$ cable.

When considering the investment in a $700 \mathrm{MW}$ cable with a compound option to expand to $1400 \mathrm{MW}$ separately, the first stage of the investment should be undertaken when the annual revenues from a $700 \mathrm{MW}$ cable reach $€ 111.1$ million. Upgrading the $700 \mathrm{MW}$ project to $1400 \mathrm{MW}$ should occur when 
the annual revenues from a $1400 \mathrm{MW}$ cable reaches $€ 249.1$ million. ${ }^{8}$ When separately considering the investment in a $1400 \mathrm{MW}$ cable, the investment should be undertaken when the annual revenues from a $1400 \mathrm{MW}$ cable reaches $€ 173.1$ million. $^{9}$

The optimal timing of an investment is when the option value and the NPV of the project are equal. Figure 3 plots the NPV of both the $700 \mathrm{MW}$ cable with an upgrade opportunity, the NPV of the $1400 \mathrm{MW}$ cable, and the option value. The figure also displays the added value from the option. Note that the revenues from the $1400 \mathrm{MW}$ cable is given as $1.81(\delta)$ times the revenue from a $700 \mathrm{MW}$ cable. ${ }^{10}$ As Figure 3 reveals, the option value and the NPV of the $1400 \mathrm{MW}$ cable are equal when the annual revenues from a $1400 \mathrm{MW}$ cable are $€ 173.1$ million. $^{11}$

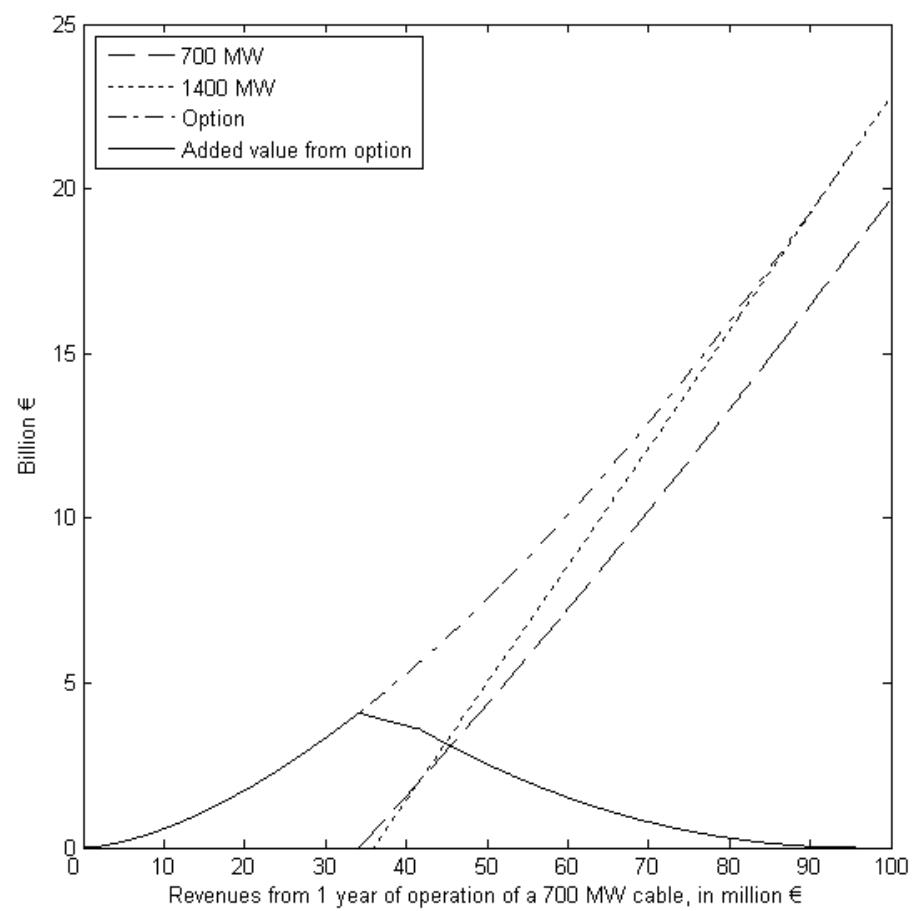

Figure 3: The NPV of $700 \mathrm{MW}$ a cable with upgrade opportunity is given by the dashed line, the NPV of a $1400 \mathrm{MW}$ as fraction of a $700 \mathrm{MW}$ cable is given by the dotted line, and the dash-dotted line gives the option value of the investment opportunity. The solid line represents the added value from the option (compared to only analyzing the NPV). Note that the $\mathrm{x}$-axis gives annual revenues from operating a $700 \mathrm{MW}$ cable, in million $€$. The revenue from a $1400 \mathrm{MW}$ cable is $\delta$ times greater than the revenue from a $700 \mathrm{MW}$ cable.

In the figure, the added value from the option, compared to only studying the NPV, is given by the solid line. The option value depends on the magnitude of the annual revenues, and reaches its maximum when the NPV of the $700 \mathrm{MW}$ project is zero. When the annual revenues approach the trigger level for the investment, the option value converges to zero. If the $1400 \mathrm{MW}$ cable is built when its NPV is zero, the option value, which is close to $€ 4$ billion, will be lost. Hence, extensive values can be lost when ignoring the option value, and the magnitude of the loss depends on the size of the annual revenues.

If there had been a cable between Norway and Germany during the years 2003 to 2009, then the cable

\footnotetext{
$8 € 137.6$ million $* \quad \delta=€ 249.1$ million, $\delta=1.81$.

${ }^{9} € 95.75$ million $* \delta=€ 173.1$ million, $\delta=1.81$.

${ }^{10}$ The X-axis gives annual revenues from a $700 \mathrm{MW}$ submarine cable. The revenues from a $1400 \mathrm{MW}$ cable are 1.81 times the revenues from a $700 \mathrm{MW}$ cable.

${ }^{11} € 95.75$ million $* 1.81=€ 173.1$ million. See also footnote 10.
} 
would have generated the annual revenues as presented in Figure 4. The assumption for the historical revenues is a cable of $1400 \mathrm{MW}$, giving a reduction in the price difference of $17 \%$, the loss is $5 \%$, and the availability is $97.4 \%$. Revenues are discounted at $7 \%$. The price difference are based on the Phelix on the EEX and NO1 prices on Nord Pool. As can be seen from the figure, the trigger level of investment in a $1400 \mathrm{MW}$ cable was reached in 2008. However, the investment decision must be made on the basis of the current value, or the belief of what the current value is.

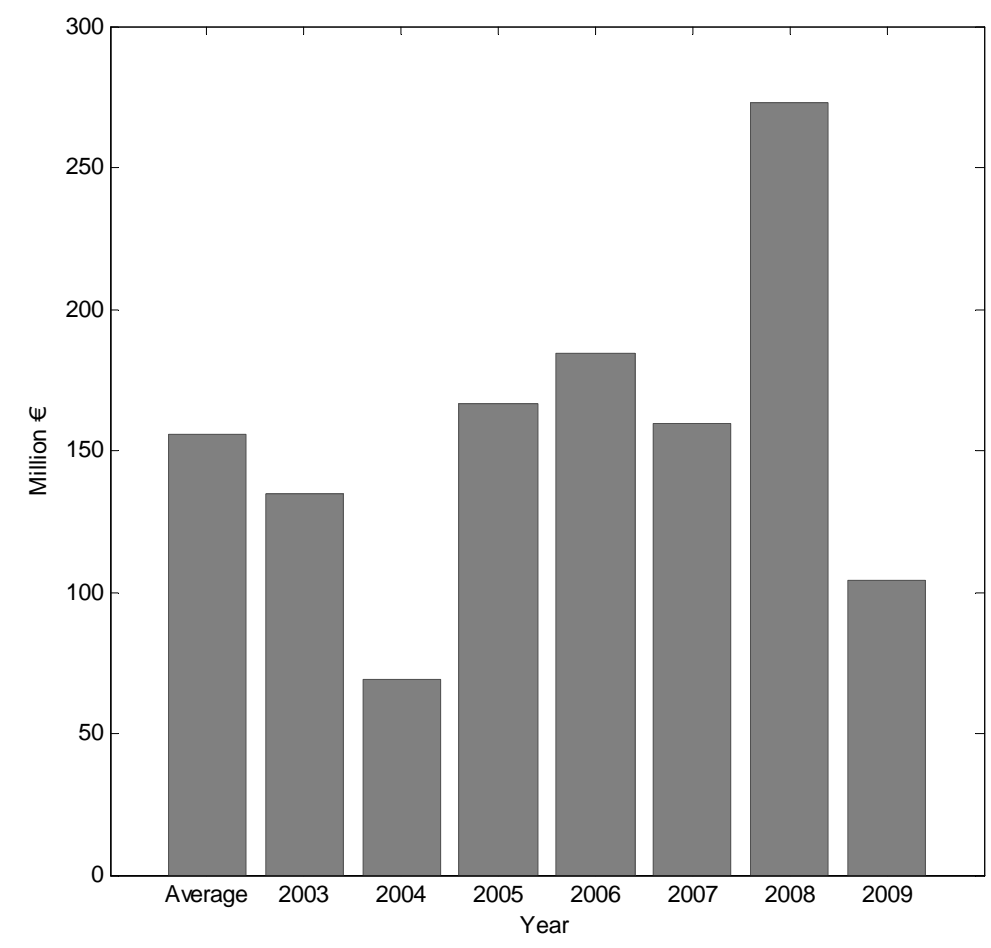

Figure 4: Annual historical revenues from a hypothetical 1400 MW cable between Norway and Germany.

\subsection{Lost Social Welfare}

If the investment is not undertaken at the optimal time, then parts of the option value will be lost, and society will not have its welfare maximized. If the time span of the grant from NVE is not sufficient for the optimal time to be reached, the investment may be undertaken (due to positive NPV), option value lost, and hence value to the society will be lost. The loss equals the difference between the NPV and the option value embedded in the investment alternative, as outlined in Figure 3. For this reason, it is important that the conditions for the license do not force investment to be undertaken before the optimal time. On the other hand, a relinquishment requirement retains some degree of control at the hands of the government, and may increase perceived predictability from the regulator's point-of-view.

\subsection{Trigger Level and Price Difference Reduction due the the Cable Itself}

When interconnecting two regions by transmission capacity, electricity will be transferred between the two regions and the price difference will decrease. It is highly uncertain how much a cable between Norway and Germany will affect the electricity price difference between the two regions. For this reason, we conducted a sensitivity analysis where we let the price difference reduction due to a $1400 \mathrm{MW}$ cable vary. This testing revealed that the volatility and drift of the project stayed approximately the same when changing the percentage of which the cable would reduce the price difference. The implication of the reduced price difference when the volatility and drift of the project stay the same, is that it will take 
longer until the trigger-level is reached, since this reduces the profitability of the cable.

\subsection{Trigger Level when Annual Price Difference Level Increases}

In the bottom-up model, changes due to the cable itself are accounted for. The price difference between Norway and Germany may change due to climate and policy measures, changes in production portfolios etc. This problem has been studied in the CELECT project at Ragnar Frisch Centre for Economic Research using the LIBEMOD model (Aune et al., 2008). They find that the electricity price difference between Norway and Germany will increase to approximately $10 € /$ MWh in 2030 (Ragnar Frisch Centre for Economic Research, 2009).

We study these structural changes in our sensitivity analysis by changing the annual mean level, $\bar{\theta}$, in Eq. (5). We let the mean annual price difference level converge to $10 € / \mathrm{MWh}$ towards 2030 by changing $\bar{\theta}$ in Eq. (5).

Given the increased mean annual price difference level, the volatility of the investment opportunity decreases to $20.8 \%$ and the drift increases to $3.6 \%$. The option value and the NPV of the $1400 \mathrm{MW}$ cable are equal when the annual revenues from a $1400 \mathrm{MW}$ cable increase to $€ 176.6$ million. ${ }^{12}$ Hence, an increased mean annual price level supports investment at a later stage. A higher drift parameter makes it more worthwhile waiting to invest whereas lower volatility triggers investment at an earlier stage. In this case, the latter effect is dominated and the trigger value increases. On the other hand, the increased drift parameter will contribute to reaching the trigger level at an earlier stage.

\subsection{Trigger Level and Sensitivity to Volatility and Discount Rate}

The trigger level of the real option depends on the volatility and the discount rate of the project. Figure 5 shows how the trigger level of the option to invest in a $1400 \mathrm{MW}$ cable depends on the volatility (dashed line) and the discount rate (solid line) of the project. When analyzing the trigger level as a function of the volatility, the discount rate is kept constant at $7 \%$ and when analyzing the trigger level as a function of the discount rate, the volatility is kept constant at $30 \%$.

$12 € 97.57$ million $* 1.81=€ 176.6$ million. See also footnote 10. 


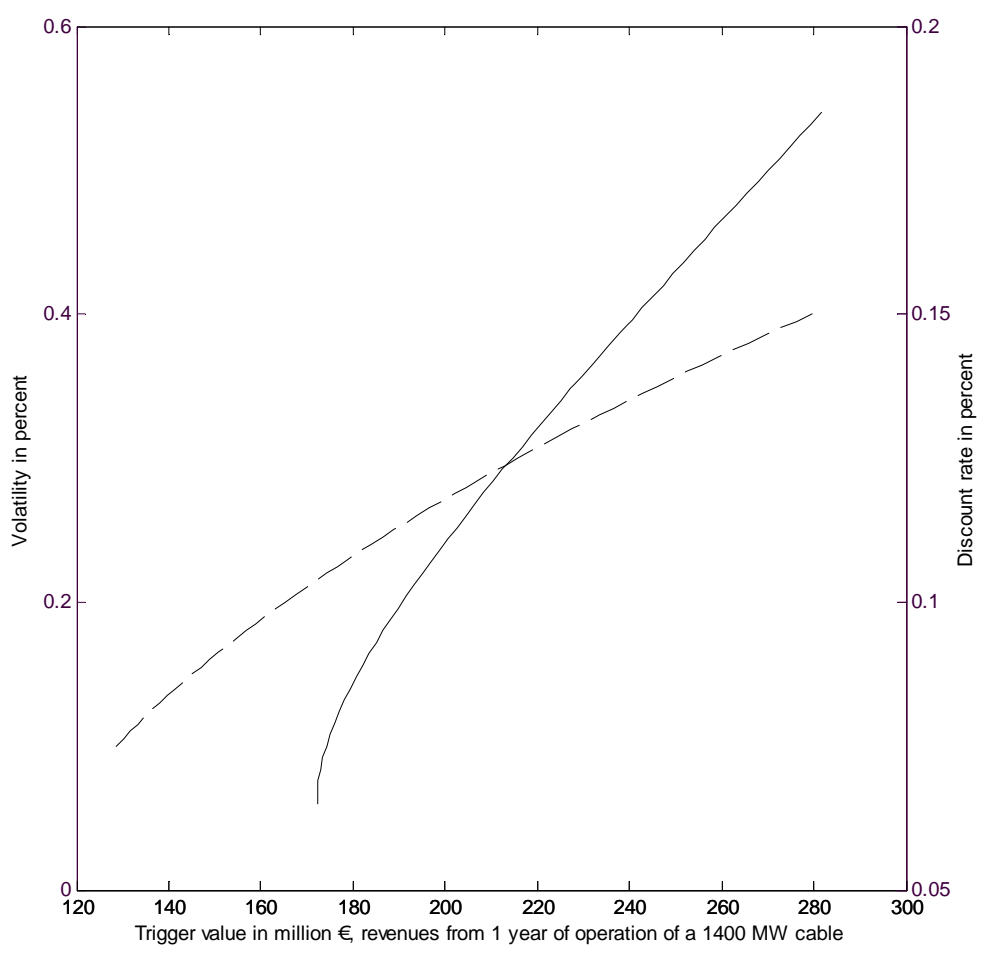

Figure 5: Trigger level of investment in a $1400 \mathrm{MW}$ cable as a function of volatility (dotted line) and discount rate (solid line). The $\mathrm{x}$-axis gives the trigger level as present value of annual revenues from a $1400 \mathrm{MW}$ cable. The left y-axis gives volatility and the right y-axis gives discount rate of the investment project.

As can be seen from the figure, both increased volatility and increased discount rate increase the trigger level of the investment. Increased volatility will make it more worthwhile to wait and see the development of the annual revenues. The risk of investing too early increases, and, hence, the threshold for investing increases. If, for instance, the share of wind power in Germany increases, this may contribute to an increase in the volatility of the annual revenues from a cable. Therefore, waiting for information on the development of politics and construction in Germany may be worthwhile.

The discount factor decides the size of the factor by which future revenues are multiplied in order to obtain the present value. An increased discount factor reduces the present value of future revenues and thereby also reduces the value of the investment project. The threshold for investment increases to compensate for the decreased value of future revenues.

As can also be seen from the figure, the volatility of the project is of higher importance to the trigger level compared to the discount rate. This gives the investor incentives to study the volatility and increase the effort in estimating this parameter.

\section{Conclusions}

In this paper, we have studied the investment opportunity of constructing a HVDC submarine cable between Norway and Germany. The profitability of investment in transmission capacity between two countries depends to a great extent on the electricity price difference between the regions. Since the cable itself will affect the price difference, this must be taken into account when considering investment in transmission capacity. 
The investment alternatives under consideration in this paper are a $700 \mathrm{MW}$ submarine cable with a compound option of expanding the investment to $1400 \mathrm{MW}$, and the alternative of building a $1400 \mathrm{MW}$ cable. By combining information from an external bottom-up model with analysis in our top-down model, we are able to take the price-effect of the new cable into account.

We find that investment in a $1400 \mathrm{MW}$ cable dominates the alternative of investing sequentially in $700 \mathrm{MW}$. The investment should be undertaken when the value of the state variable, that is, the present value of annual revenues, reaches the trigger level. Increased volatility of the annual revenues magnifies the trigger level. This suggests that policy measures and other market characteristics which increases the volatility of the annual revenues from a cable, will contribute to postponing investment projects. A time limited license to construct transmission capacity may initiate investment in projects with positive NPV, but which should be delayed until the trigger value is reached for the purpose of maximizing social welfare.

For future work, we will include the uncertainty of the availability of lay vessels and trenching spreads as there are limitations in the production and delivery capacity of the companies to manufacture these large cables. Finally, we would like to include the time lag between the date the investment is decided upon and the date, from which the capacity is available for transmission. 


\section{Appendix}

Table 4: Results from OLS, deterministic price variation.

\begin{tabular}{|c|c|c|c|c|c|}
\hline & Coefficient & Std.Error & t-value & t-prob & Part. $R^{2}$ \\
\hline Constant & -20.3536 & 0.7202 & -28.3 & 0.0000 & 0.0129 \\
\hline hour 2 & -3.61377 & 0.7294 & -4.95 & 0.0000 & 0.0004 \\
\hline hour3 & -5.91366 & 0.7294 & -8.11 & 0.0000 & 0.0011 \\
\hline hour4 & -7.50769 & 0.7294 & -10.3 & 0.0000 & 0.0017 \\
\hline hour5 & -7.14553 & 0.7294 & -9.80 & 0.0000 & 0.0016 \\
\hline hour6 & -3.54529 & 0.7294 & -4.86 & 0.0000 & 0.0004 \\
\hline hour7 & 0.389271 & 0.7294 & 0.534 & 0.5936 & 0.0000 \\
\hline hour8 & 12.0712 & 0.7294 & 16.5 & 0.0000 & 0.0044 \\
\hline hour9 & 15.8539 & 0.7294 & 21.7 & 0.0000 & 0.0076 \\
\hline hour 10 & 19.5436 & 0.7294 & 26.8 & 0.0000 & 0.0116 \\
\hline hour 11 & 22.6130 & 0.7294 & 31.0 & 0.0000 & 0.0154 \\
\hline hour 12 & 29.3997 & 0.7294 & 40.3 & 0.0000 & 0.0258 \\
\hline hour 13 & 22.2097 & 0.7294 & 30.4 & 0.0000 & 0.0149 \\
\hline hour 14 & 19.6317 & 0.7294 & 26.9 & 0.0000 & 0.0117 \\
\hline hour 15 & 16.5456 & 0.7294 & 22.7 & 0.0000 & 0.0083 \\
\hline hour 16 & 13.4611 & 0.7294 & 18.5 & 0.0000 & 0.0055 \\
\hline hour 17 & 12.3399 & 0.7294 & 16.9 & 0.0000 & 0.0046 \\
\hline hour 18 & 17.3724 & 0.7294 & 23.8 & 0.0000 & 0.0092 \\
\hline hour 19 & 22.0043 & 0.7294 & 30.2 & 0.0000 & 0.0146 \\
\hline hour 20 & 17.2519 & 0.7294 & 23.7 & 0.0000 & 0.0090 \\
\hline hour 21 & 14.0853 & 0.7294 & 19.3 & 0.0000 & 0.0060 \\
\hline hour 22 & 9.10171 & 0.7294 & 12.5 & 0.0000 & 0.0025 \\
\hline hour 23 & 8.10882 & 0.7294 & 11.1 & 0.0000 & 0.0020 \\
\hline hour 24 & 1.96651 & 0.7294 & 2.70 & 0.0070 & 0.0001 \\
\hline Tuesday & 3.72364 & 0.3941 & 9.45 & 0.0000 & 0.0015 \\
\hline Wednesday & 2.77978 & 0.3938 & 7.06 & 0.0000 & 0.0008 \\
\hline Thursday & 2.47527 & 0.3938 & 6.29 & 0.0000 & 0.0006 \\
\hline Friday & -0.907252 & 0.3941 & -2.30 & 0.0213 & 0.0001 \\
\hline Saturday & -8.93107 & 0.3941 & -22.7 & 0.0000 & 0.0083 \\
\hline Sunday & -15.8722 & 0.3941 & -40.3 & 0.0000 & 0.0258 \\
\hline February & 6.01004 & 0.5232 & 11.5 & 0.0000 & 0.0021 \\
\hline March & 3.52531 & 0.5111 & 6.90 & 0.0000 & 0.0008 \\
\hline April & 2.05104 & 0.5154 & 3.98 & 0.0001 & 0.0003 \\
\hline May & 3.68943 & 0.5111 & 7.22 & 0.0000 & 0.0008 \\
\hline June & 8.05756 & 0.5154 & 15.6 & 0.0000 & 0.0040 \\
\hline July & 11.1669 & 0.5111 & 21.8 & 0.0000 & 0.0077 \\
\hline August & 0.474376 & 0.5111 & 0.928 & 0.3534 & 0.0000 \\
\hline September & 5.01484 & 0.5154 & 9.73 & 0.0000 & 0.0015 \\
\hline October & 6.91317 & 0.5111 & 13.5 & 0.0000 & 0.0030 \\
\hline November & 7.28393 & 0.5154 & 14.1 & 0.0000 & 0.0032 \\
\hline December & 4.10956 & 0.5111 & 8.04 & 0.0000 & 0.0011 \\
\hline$y 2004$ & 6.76529 & 0.3941 & 17.2 & 0.0000 & 0.0048 \\
\hline$y 2005$ & 24.4756 & 0.3941 & 62.1 & 0.0000 & 0.0592 \\
\hline$y 2006$ & 9.26613 & 0.3941 & 23.5 & 0.0000 & 0.0089 \\
\hline$y 2007$ & 19.9292 & 0.3941 & 50.6 & 0.0000 & 0.0400 \\
\hline$y 2008$ & 34.2323 & 0.3941 & 86.9 & 0.0000 & 0.1096 \\
\hline$y 2009$ & 12.7108 & 0.3936 & 32.3 & 0.0000 & 0.0167 \\
\hline
\end{tabular}


Table 5: Annual price level parameters for Eq. (5).

\begin{tabular}{ll}
\hline & \\
Coefficient & Value \\
\hline $\bar{\theta}$ & -5.01 \\
$\varrho$ & 11.65 \\
\hline
\end{tabular}

Table 6: Parameters for exchange rate model.

\begin{tabular}{ll} 
Coefficient & Value \\
\hline$E_{0}$ & $8.13 \mathrm{NOK} / €$ \\
$\varpi$ & 0.05 \\
\hline
\end{tabular}

Table 7: Technical parameters for transmission capacity.

\begin{tabular}{ll}
\hline Parameter & Parameter value \\
\hline Capacity 1 $\left(c_{700}\right)$ & $700 \mathrm{MW}$ \\
Capacity $2\left(c_{1400}\right)$ & $1400 \mathrm{MW}$ \\
Investment cost $700 \mathrm{MW}\left(K_{700}\right)$ & $€ 819 \mathrm{mill}$ \\
Investment cost $1400 \mathrm{MW}\left(K_{1400}\right)$ & $€ 1.276$ mill \\
Annual cost, $700 \mathrm{MW}\left(q_{700}\right)$ & $€ 4.3 \mathrm{mill}^{a}$ \\
Annual cost, $1400 \mathrm{MW}\left(q_{1400}\right)$ & $€ 8.7 \mathrm{mill}{ }^{b}$ \\
Availability $(b)$ & $97.4 \%$ \\
Loss $(k)$ & $5 \%$ \\
Price reduction, $700 \mathrm{MW}\left(u_{700}\right)$ & $8.4 \%$ \\
Price reduction, $1400 \mathrm{MW}\left(u_{1400}\right)$ & $16.8 \%$ \\
\hline
\end{tabular}

${ }^{a}$ The maintenance cost of a $600 \mathrm{MW}$ cable is $€ 4$ million per year (estimated costs in the NorNed project), while that of a $700 \mathrm{MW}$ cable is (€4 million/600MW)*700 MW. The annual costs are divided into daily costs.

${ }^{b}$ The maintenance cost of $1400 \mathrm{MW}$ is twice as high as the maintenance cost of $700 \mathrm{MW}$. The annual costs are divided into daily costs.

Table 8: Parameters for the real options valuation.

\begin{tabular}{ll}
\hline Parameter & Parameter value \\
\hline$\mu$ & $2.97 \%$ \\
$\sigma$ & $21.7 \%$ \\
$\delta$ & 1.81 \\
$\rho$ & $7 \%$ \\
\hline
\end{tabular}

\section{Acknowledgments}

The authors would like to thank Bjørn Grinden in SINTEF Energy Research for contributing with valuable results from the EMPS model. We acknowledge the generous financial support from the Research Council 
of Norway, Agder Energi and Troms Kraft, and through the ELDEV project at Sør-Trøndelag University College.

\section{References}

Aune, F., Golombek, R., Kittelsen, S., Rosendahl, K., 2008. Liberalizing European energy markets: an economic analysis. Edward Elgar Publishing.

Bahrman, M., Johnson, B., 2007. The ABCs for HVDC transmission technologies. IEEE Power and Energy Magazine 5 (2), 32-44.

Böhringer, C., 1998. The synthesis of bottom-up and top-down in energy policy modeling. Energy Economics 20 (3), 233-248.

Borovkova, S., Permana, F., 2006. Modelling electricity prices by the potential jump-diffusion. Chapter 9 in: Shiryaev, A.N., Grossinho, M.d.R., Oliveira, P.E., Esquvel, M.L. (eds), Stochastic finance. Springer.

Botterud, A., 2003. Long-term planning in restructured power systems: dynamic modelling of investments in new power generation under uncertainty, Ph.D. thesis, Norwegian University of Science and Technology.

Bunn, D., Zachmann, G., 2010. Inefficient arbitrage in inter-regional electricity transmission. Journal of Regulatory Economics 37 (3), 243-265.

Chortareas, G., Kapetanios, G., Shin, Y., 2002. Nonlinear mean reversion in real exchange rates. Economics Letters 77 (3), 411-417.

Copeland, T., Antikarov, V., 2003. Real options: a practitioner's guide. Texere.

Dangl, T., Wirl, F., 2004. Investment under uncertainty: calculating the value function when the Bellman equation cannot be solved analytically. Journal of Economic Dynamics and Control 28 (7), 1437-1460.

Décamps, J., Mariotti, T., Villeneuve, S., 2006. Irreversible investment in alternative projects. Economic Theory 28 (2), 425-448.

Deng, S., 1999. Financial methods in competitive electricity markets, Ph.D. thesis, University of California, Berkeley.

Deutsches Windenergie-Institut, 2008. Windenergie in Deutschland - Aufstellungszahlen für das Jahr 2008.

Dixit, A. K., Pindyck, R. S., 1994. Investment under uncertainty. Princeton University Press.

Econ Pöyry, 2009. The Econ Bid model. http://www.econ.no/modules/module_123/proxy. $\operatorname{asp} ? \mathrm{D}=2 \& \mathrm{C}=147 \& I=683$, [cited 18 February 2010].

EIA, 2008. Energy Information Administration, Independent statistics and analysis. http://tonto. eia.doe.gov/country/countryenergydata. cfm?fips=GM, [cited 5 January 2010].

Elkraft System, 2009. The Balmorel model. http://www.balmorel.com, [cited 18 February 2010].

Elverhøi, M., Fleten, S.-E., Fuss, S., Heggedal, A. M., Szolgayova, J., Troland, O. C., 2009. Hydropower upgrade projects - a real options approach, Working paper, Department of Industrial Economics and Technology Management, Norwegian University of Science and Technology.

Engel, C., West, K., 2004. Accounting for exchange-rate variability in present-value models when the discount factor is near 1. The American Economic Review 94 (2), 119-125. 
European Commission, 2008. Directive 2009/29/EC of the European Parliament and of the Council of 23 April 2009 on the promotion of the use of energy from renewable sources and amending and subsequently repealing directives 2001/77/EC and 2003/30/EC. http://eur-lex.europa.eu/LexUriServ/ LexUriServ.do?uri=OJ:L:2009:140:0016:0062:EN:PDF, [cited 1 February 2010].

Fortin, I., Fuss, S., Hlouskova, J., Khabarov, N., Obersteiner, M., Szolgayova, J., 2008. An integrated $\mathrm{CVaR}$ and real options approach to investments in the energy sector. The Journal of Energy Markets $1(2), 61-85$.

Fuss, S., Szolgayova, J., Obersteiner, M., Gusti, M., 2008. Investment under market and climate policy uncertainty. Applied Energy 85 (8), 708-721.

Godinho, P., 2006. Monte Carlo estimation of project volatility for real options analysis. Journal of Applied Finance 16 (1), 15-31.

Guthrie, G., Videbeck, S., 2007. Electricity spot price dynamics: beyond financial models. Energy Policy 35 (11), 5614-5621.

Haas, R., Schipper, L., 1998. Residental energy demand in OECD-countries and the role of irreversible efficiency improvements. Energy Economics 20 (4), 421-442.

Joskow, P. L., Tirole, J., 2005. Merchant transmission investment. The Journal of Industrial Economics $53(2), 233-264$.

Lu, X., Dong, Z., Li, X., 2005. Electricity market price spike forecast with data mining techniques. Electric Power Systems Research 73 (1), 19-29.

Lucia, J. J., Schwartz, E. S., 2002. Electricity prices and power derivatives: evidence from the Nordic power exchange. Review of Derivatives Research 5 (1), 5-50.

Mussa, M., 1979. Empirical regularities in the behavior of exchange rates and theories of the foreign exchange market. Carnegie-Rochester Conference Series on Public Policy 11 (1), 9-57.

Newton, D., Paxson, D., Widdicks, M., 2004. Real R\&D options. International Journal of Management Reviews 5-6 (2), 113-130.

Nordel, 2008. Annual Statistics 2008.

Norwegian Government, 2010. Norges Lover, Norwegian Laws. Norwegian Government, act relating to the generation, conversion, transmission, trading, distribution and use of energy etc.

Ragnar Frisch Centre for Economic Research, 2009. Simulations using the LIBEMOD model within the CELECT project.

Samuelson, P., 1965. Proof that properly anticipated prices fluctuate randomly. Industrial Management Review 6 (2), 41-49.

Siddiqui, A., Gupta, H., 2007. Transmission investment timing and sizing under uncertainty, Working paper, Department of Statistical Science, University College London.

SINTEF Energy Research AS, 2009. EMPS model, multi area power market simulator. http://www.sintef.no/Home/Petroleum-and-Energy/SINTEF-Energy-Research/ Software/EOPS-and-EMPS/, [cited 18 February 2010].

Song, Y., Johns, A., 2006. Flexible AC transmission systems, FACTS. The Institution of Electrical Engineers.

Statnett, 2004. Teknisk beskrivelse (Technical description of the NorNed cable), report ID 292388.

Trigeorgis, L., 1996. Real options: managerial flexibility and strategy in resource allocation. The MIT Press.

Weron, R., Bierbrauer, M., Trück, S., 2004. Modeling electricity prices: jump diffusion and regime switching. Physica A 336 (1-2), 39-48. 